\title{
Time course of circulatory and metabolic recovery of cat brain after cardiac arrest assessed by perfusion- and diffusion-weighted imaging and MR-spectroscopy
}

\author{
Henning Krep ${ }^{\mathrm{b}, *}$, Bernd W. Böttiger ${ }^{\mathrm{c}}$, Christian Bock $^{\mathrm{a}}$, Christian M. Kerskens ${ }^{\mathrm{a}}$, \\ Bernd Radermacher ${ }^{\mathrm{a}}$, Matthias Fischer ${ }^{\mathrm{b}}$, Mathias Hoehn ${ }^{\mathrm{a}}$, Konstantin- \\ Alexander Hossmann ${ }^{\text {a }}$ \\ ${ }^{a}$ The Max-Planck-Institute for Neurological Research, Department of Experimental Neurology, D-50931 Cologne, Gleuelerstr. 50, Germany \\ ${ }^{\mathrm{b}}$ Department of Anesthesia and Intensive Care Medicine, University Hospital Bonn, Sigmund-Freud-Str. 25, Bonn, Germany \\ ${ }^{\mathrm{c}}$ Department of Anesthesiology, University of Heidelberg, Heidelberg, Germany
}

\begin{abstract}
Brain recovery after cardiac arrest (CA) was assessed in cats using arterial spin tagging perfusion-weighted imaging (PWI), diffusion-weighted imaging (DWI), and ${ }^{1} \mathrm{H}$-spectroscopy $\left({ }^{1} \mathrm{H}\right.$-MRS). Cerebral reperfusion and metabolic recovery was monitored in the cortex and in basal ganglia for $6 \mathrm{~h}$ after cardiopulmonary resuscitation (CPR). Furthermore, the effects of an hypertonic/ hyperoncotic solution ( $7.5 \% \mathrm{NaCl} / 6 \%$ hydroxyl ethyl starch, HES) and a tissue-type plasminogen activator (TPA), applied during CPR, were assessed on brain recovery. CA and CPR were carried out in the MR scanner by remote control. CA for 15-20 min was induced by electrical fibrillation of the heart, followed by CPR using a pneumatic vest. PWI after successful CPR revealed initial cerebral hyperperfusion followed by delayed hypoperfusion. Initial cerebral recirculation was improved after osmotic treatment. Osmotic and thrombolytic therapy were ineffective in ameliorating delayed hypoperfusion. Calculation of the apparent diffusion coefficient (ADC) from DWI demonstrated complete recovery of ion and water homeostasis in all animals. ${ }^{1} \mathrm{H}-\mathrm{MRS}$ measurements of lactate suggested an extended preservation of post-ischaemic anaerobic metabolism after TPA treatment. The combination of noninvasive MR techniques is a powerful tool for the evaluation of therapeutical strategies on circulatory and metabolic cerebral recovery after experimental cerebral ischaemia.
\end{abstract}

(C) 2003 Elsevier Ireland Ltd. All rights reserved.

Keywords: Cardiac arrest; Cardiopulmonary resuscitation; Cerebral blood flow; Magnetic resonance techniques; Hypertonic solutions; Thrombolysis

\section{Resumo}

Avaliou-se a recuperação cerebral de gatos após paragem cardíaca (CA)..... com imagens de avaliação da perfusão (PWI) e imagens de avaliação da difusão (DWI) em espectrofotometria ${ }^{1} \mathrm{H}\left({ }^{1} \mathrm{H}-\mathrm{MRS}\right)$. A perfusão cerebral foi monitorizada no córtex e nos gânglios da base durante seis horas a seguir à reanimação cardio-pulmonar (CPR). Avaliaram-se ainda os efeitos de uma solução hiperosmótica e hiperoncótica ( $\mathrm{NaCl}$ hipertónico 7.5\% / hidroxi etil starch $\mathrm{HES} \mathrm{a} \mathrm{6 \% )} \mathrm{e} \mathrm{um} \mathrm{activador} \mathrm{tecidular} \mathrm{do} \mathrm{plasminogéneo}$ (TPA), administrado durante a reanimação e avaliado na fase de recuperação. A CA e a RCP foram executadas, por controlo remoto, no scanner da ressonância magnética. A CA foi induzida, por descarga eléctrica, durante 15-20 min, sendo a reanimação feita por colete pneumático. A PWI depois da CPR com sucesso evidenciou uma hiperperfusão cerebral inicial seguida de hipoperfusão. A recirculação cerebral inicial melhorou com a administração da solução osmótica. O tratamento osmótico e

Abbreviations: ADC, apparent diffusion coefficient of water; ALS, advanced life support; CA, cardiac arrest; CBF, cerebral blood flow; CPR, cardiopulmonary resuscitation; $\mathrm{Cr} / \mathrm{PCr}$, creatine-phosphocreatine; DWI, diffusion-weighted imaging; HHS, hypertonic-hyperoncotic solution; ${ }^{1} \mathrm{H}$ MRS, ${ }^{1} \mathrm{H}$-proton spectroscopy; PWI, perfusion-weighted imaging; ROSC, return of spontaneous circulation; TPA, tissue-type plasminogen activator.

* Corresponding author. Tel: +49-228-287-4124; fax: +49-221-287-4125.

E-mail address: h.krep@ukb.uni-bonn.de (H. Krep). 
trombolítico não preveniram a hipoperfusão tardia. O cálculo da difusão aparente (ADC) a partir do DWI demonstra uma recuperação completa, em todos os animais, da homeostasia de iões e água. A medição do lactato por ${ }^{1} \mathrm{H}-\mathrm{MRS}$ sugere uma persistência prolongada do metabolismo anaeróbio depois do tratamento com TPA. A combinação das técnicas de RM é um instrumento poderoso para avaliação das estratégias terapêuticas na recuperação da circulação e metabolismo cerebrais cerebrais no período pós isquemia cerebral experimental.

(C) 2003 Elsevier Ireland Ltd. All rights reserved.

Palavras chave: Paragem cardíaca; Reanimação cardio-pulmonar; Fluxo sanguíneo cerebral; Técnicas de ressonância magnética; Soluções hipertónicas e trombólise

\section{Resumen}

La recuperación cerebral después de un paro cardíaco (CA) fue evaluada en gatos usando imagenología de medición de perfusión arterial (PWI) con marcadores de spin, imagenología de medición de difusión (DWI), y espectroscopia- ${ }^{1} \mathrm{H}\left({ }^{1} \mathrm{H}-\mathrm{MRS}\right)$. La reperfusión cerebral y recuperación metabólica fue monitoreada en la corteza y en los ganglios basales por 6 horas después de reanimación cardiopulmonar (CPR). Se evaluó el efecto sobre la recuperación cerebral de una solución hipertónica / hiperoncótica $(7.5 \% \mathrm{NaCl} / 6 \%$ hidroxi ethyl starch, HES) y un activador de plasminógeno tisular (TPA), aplicados durante la CPR. El paro cardíaco y la reanimación fueron llevados a cabo en el tomógrafo de resonancia magnética (MR) por control remoto. Se indujo paro cardíaco por fibrilación eléctrica del corazón, se mantuvo por 15-20 minutos, seguido de CPR usando un chaleco neumático. PWI después de CPR exitosa reveló hiperperfusión cerebral inicial seguida de hipoperfusión tardía. La recirculación inicial mejoró después del tratamiento osmótico. La terapia osmótica y trombolítica fueron inefectivas en mejorar la hipoperfusión tardía. El calculo del coeficiente de difusión aparente (ADC) por medio de DWI demostró una recuperación completa de de la homeostasis de iones y de agua en los animales. Las mediciones de lactato con ${ }^{1} \mathrm{H}$-MRS sugieren una extensa preservación del metabolismo anaerobio post isquémico después del tratamiento con TPA. La combinación de técnicas no invasivas de MR es una herramienta poderosa para la evaluación de estrategias terapéuticas en recuperación circulatoria y metabólica cerebral después de isquemia cerebral experimental.

(C) 2003 Elsevier Ireland Ltd. All rights reserved.

Palabras clave: Paro cardiaco; Reanimación cardiopulmonar (RCP); Flujo sanguíneo cerebral; Técnicas de resonancia magnética; Soluciones hipertónicas; Trombolisis

\section{Introduction}

Successful resuscitation from cardiac arrest frequently is complicated by severe brain injury. About $50 \%$ of short-term survivors die in permanent coma, and 10$30 \%$ of long-term survivors suffer permanent brain damage [1]. The restoration of the functional and the biochemical integrity of the brain after a period of prolonged cardiac arrest (CA) may be severely compromised by cerebral recirculation disturbances such as the no-reflow phenomenon [2] and the delayed hypoperfusion syndrome [3]. No-reflow is characterized by incomplete post-ischaemic microvascular filling [2], exacerbated by increasing duration of ischaemia [4]. The delayed hypoperfusion syndrome develops after a transient phase of reactive hyperaemia and is associated with a disturbed coupling between blood flow and metabolism [5]. After short periods of cerebral ischaemia post-ischaemic hypoperfusion is present already after $10 \mathrm{~min}$ of recirculation [6], and after prolonged global ischaemia the disturbances may last several days [7].

Using magnetic resonance (MR) imaging and spectroscopy techniques noninvasive physiological monitoring of cerebral blood flow ( $\mathrm{CBF}$ ), metabolic integrity, and brain water homeostasis can be accomplished in experi- mental animal models of cerebral ischaemia. One of the great advantages of in vivo MR investigations of cerebral ischaemia models is the ability to perform longitudinal studies in which the relationship between the time courses of post-ischaemic CBF and metabolic recovery can be evaluated in various brain structures. In the present study, perfusion-weighted imaging (PWI) was performed, for the first time, in a feline model of prolonged $\mathrm{CA}$ and cardiopulmonary resuscitation (CPR) by an ultrafast version of the arterial spin tagging method based on snapshot FLASH imaging. This method allows recording of fast cerebral perfusion changes in rats $[8,9]$, and has not been employed before to describe the post-ischaemic CBF variations in experimental models of global cerebral ischaemia. Diffusionweighted imaging (DWI) was used to calculate the apparent diffusion coefficient of water (ADC). The ADC is sensitive to alterations of intracellular water homeostasis and cell volume, and is able to differentiate between reversible and irreversible brain injury [10-13]. Finally, localized ${ }^{1} \mathrm{H}$-spectroscopy $\left({ }^{1} \mathrm{H}\right.$-MRS) was used to monitor the lactate changes in the brain as a measure of anaerobic metabolic activity $[14,15]$.

Brain resuscitation and neurological recovery after prolonged CA requires successful treatment of cerebral recirculation disturbances. A close relationship between 
prevention of no-reflow $[16,17]$ treatment of delayed hypoperfusion $[18,19]$ and the functional cerebral recovery process has been established. In earlier investigations of our laboratory it was demonstrated that the combination of standard advanced life support [20] with application of either a hypertonic/hyperoncotic solution $(7.5 \% \mathrm{NaCl}$ in $6 \%$ hydroxy ethyl starch) or a tissue-type plasminogen-activator (TPA) significantly reduced cerebral no-reflow [21,22]. The effects of these newer therapeutical approaches on post-ischaemic cerebral reperfusion characteristics and, in particular, the delayed hypoperfusion syndrome have not been evaluated to date.

In this paper we describe an investigation in which an array of MR techniques including PWI, DWI, and ${ }^{1} \mathrm{H}-$ MRS has been employed to evaluate post-ischaemic cerebral reperfusion and metabolic recovery in cats during the first $6 \mathrm{~h}$ after resuscitation from prolonged CA. Furthermore, the effects of osmotic or thrombolytic therapy, both initiated with the onset of CPR, on the MR variables were assessed. Induction of $C A$ and $C P R$ were remotely performed in the MR scanner allowing us to perform repeated measurements throughout the recirculation period beginning with the return of spontaneous circulation.

\section{Material and methods}

\subsection{General preparation and recording of physiological variables}

All experiments were carried out in accordance with the German legislation on animal care, and approved by the local authorities. In twelve adult male mongrel cats $(2.9-3.4 \mathrm{~kg})$ anaesthesia was initiated by inhalation of halothane in $\mathrm{N}_{2} \mathrm{O} / \mathrm{O}_{2}(7 / 3)$. After tracheal intubation the animals were immobilized (pancuronium bromide 0.12 $\mathrm{mg} / \mathrm{kg} / \mathrm{h}$ ) and mechanically ventilated (Harvard Apparatus, South Natick, MA). Tidal volume and ventilation rate were adjusted to maintain an end-exspiratory carbon dioxide pressure $\left(\mathrm{EtCO}_{2}\right)$ of $35-40 \mathrm{mmHg}$. A femoral artery and vein were cannulated with $3 \mathrm{~F} / 5 \mathrm{~F}$ catheters for measurement of arterial blood pressure, blood sampling, and for drug and fluid administration. Via the contralateral femoral vein a $3 \mathrm{~F}$ pacing catheter (Vygon, Aachen, Germany) was placed into the right atrium for intracardial ECG recording. Rectal temperature was measured with a thermistor probe and kept constant at $37{ }^{\circ} \mathrm{C}$ using a feed-back controlled warm water jacket. After completion of surgical preparations, the animals were turned to the prone position and two flat, flexible copper defibrillator electrodes were attached to the chest. Then, an inflatable vest developed for extrathoracal cardiac compression was placed around the thorax and connected to a compressor.
During CPR the vest was inflated with pressurized nitrogen at a rate of $80-120 / \mathrm{min}$ until spontaneous cardiac function returned. Finally, the animals were fixed in a non-magnetic headholder and positioned in the magnet of the MR scanner.

The MABP was measured continuously using highfidelity pressure transducers (Braun Medical AG, Melsungen, Germany), and $\mathrm{EtCO}_{2}$ was monitored with a medical gas analyzer LB2 (Sensor Medica Corp., Anaheim, CA, USA). Data were recorded on an eightchannel polygraph (5525 C Dynograph, Beckman Instruments, IL) and processed on a PC running the DasyLab data acquisition software (Datalog, Mönchengladbach, Germany). Arterial blood samples were taken at defined time points for analysis of blood gases and electrolytes (blood gas system 288, Bayer Diagnostics, Fernwald, Germany), and glucose (glucose analyzer 2, Beckman Instr., Fullerton, CA).

\subsection{Cardiac arrest and resuscitation protocol}

The animals were randomly assigned to one of the following resuscitation protocols: (1) standard CPR according to the AHA guidelines [20]; (2) CPR in combination with osmotic therapy by i.v. infusion of a hypertonic/hyperoncotic solution (HHS); (3) CPR in combination with thrombolytic therapy by i.v. injection of a tissue-type plasminogen-activator (TPA; Actilyse ${ }^{\circledR}$, Boehringer-Ingelheim, Ingelheim, Germany) and heparin.

CA and CPR were carried out in the magnet of the MR scanner by remote control. CA was induced by electrical fibrillation for $1 \mathrm{~min}(\mathrm{AC} 30 \mathrm{~V}, 5 \mathrm{~mA}, 50 \mathrm{~Hz})$ through the pacing catheter. During CA, mechanical ventilation, anaesthesia, and infusions were interrupted and the heating system was switched off. CPR was started after 15-20 min CA with i.v. injection of $0.2 \mathrm{mg} /$ $\mathrm{kg}$ adrenaline (epinephrine) followed by extrathoracic cardiac compression using the pneumatic vest. Artificial ventilation was resumed with $100 \% \mathrm{O}_{2}$ at a rate $50 \%$ above control and the heating system was restarted. At this time, either osmotic or thrombolytic therapy was initiated. For osmotic therapy, $2 \mathrm{ml} / \mathrm{kg}$ HHS were infused over $10 \mathrm{~min}$, and thrombolytic therapy was started with a bolus injection of $1 \mathrm{mg} / \mathrm{kg}$ TPA and 100 IE/ $\mathrm{kg}$ heparin followed by the infusion of $1 \mathrm{mg} / \mathrm{kg}$ TPA over $30 \mathrm{~min}$. Animals of the standard CPR group received $2 \mathrm{ml} / \mathrm{kg} / 10$ min Ringer's solution. After $3 \mathrm{~min}$ of chest compression, the first defibrillation $(20 \mathrm{~J})$ was carried out using the external defibrillator electrodes. If the defibrillation failed to induce return of spontaneous circulation (ROSC), an additional dose of adrenaline was injected and the heart massage was continued for another $3 \mathrm{~min}$ until the next defibrillation was performed. After ROSC, $1 \mathrm{mEq} / \mathrm{kg} / 10$ min sodium bicar- 
bonate $\left(\mathrm{NaHCO}_{3}\right)$ were infused, and Ringer's solution and pancuronium infusions were resumed.

\subsection{NMR measurements}

NMR measurements were performed on a $47 / 30$ Bruker BIOSPEC MSL-X11 system (Bruker, Ettlingen, Germany) using a $4.7 \mathrm{~T} 30 \mathrm{~cm}$ inner diameter horizontal bore magnet equipped with actively shielded gradient coils $(100 \mathrm{mT} / \mathrm{m}$; gradient rise time $\leq 250 \mu \mathrm{s})$. A $12-\mathrm{cm}$ diameter Helmholtz coil attached to the nonmagnetic headholder was used for RF transmission, and a $4.0-\mathrm{cm}$ diameter surface coil with inductive coupling was placed over the skull of the animals for signal reception. The two coils were decoupled from each other, the transmitter coil actively and the surface coil passively. A third coil with a $4.5-\mathrm{cm}$ diameter was positioned below the neck of the animals for arterial spin tagging. Multislice sagittal pilot scans $\left(T_{\mathrm{R}}=1000 \mathrm{~ms}, T_{\mathrm{E}}=12 \mathrm{~ms}\right)$ were acquired for the selection of five coronal slices at Horsley-Clark coordinates A20-P10. The slice thickness was $3 \mathrm{~mm}$ and the interslice gap was $4 \mathrm{~mm}$.

PWI and DWI were repeatedly performed before and up to $6 \mathrm{~h}$ after $\mathrm{CA},{ }^{1} \mathrm{H}$-MRS also during $\mathrm{CA} .{ }^{1} \mathrm{H}$ spectroscopic measurements during CA were performed at defined time points, in the cortex $5 \mathrm{~min}$ and in the basal ganglia $10 \mathrm{~min}$ after the onset of CA.

PWI was performed using the ultrafast arterial spin tagging technique as previously described in detail [8]. The PWI sequence consisted of two similar image acquisition phases separated by a recovery period. Each phase comprised a magnetization preparation step and was followed by snapshot FLASH imaging. During the first phase (inversion imaging), magnetization of the blood flowing cranially through the neck was inverted adiabatically using a field sweep through the combination of a magnetic field gradient $(1 \mathrm{G} / \mathrm{m}$ applied in the $z$-direction) and an off-resonance $B_{1}$ field $(50 \mathrm{mG})$ chosen to excite a defined slice through the neck. During the second phase (control imaging), the magnetic field gradient was reversed so that inflowing spins were left undisturbed. The two images exhibited the same signal loss due to magnetization transfer effects but differed in the magnetization of the inflowing blood [23]. Perfusionweighted images were obtained by subtracting inversion and control images from each other. Snapshot FLASH acquisitions used centric phase encoding starting at zero phase gradient with a $T_{\mathrm{R}}$ of $7.4 \mathrm{~ms}$ and $T_{\mathrm{E}}$ of $3.9 \mathrm{~ms}$. RF flip angle $\alpha$ was set to $18^{\circ}$. The field of view was $8 \mathrm{~cm}$ with a slice thickness of $5 \mathrm{~mm}$, the image matrix was $128 \times 64$.

DWI was performed using a multislice StejskalTanner pulsed gradient spin-echo sequence $\left(T_{\mathrm{E}}=35.2\right.$ $\mathrm{ms}, T_{\mathrm{R}}=2325 \mathrm{~ms}$ ). Five slices with a thickness of $3 \mathrm{~mm}$ and an interslice distance of $4 \mathrm{~mm}$ were obtained. The field of view was $8 \mathrm{~cm}$ with an image matrix of $128 \times 64$ pixels. For quantitative determination of the ADC, images were recorded with two different diffusionweighting factors $b \quad\left(b=20\right.$ and $\left.1500 \mathrm{~s} / \mathrm{mm}^{2}\right)$. To improve temporal resolution, unweighted spin echoes $\left(b=0 \mathrm{~s} / \mathrm{mm}^{2}\right)$ were recorded intermittently and combined with the subsequently recorded weighted spin echoes $\left(b=1500 \mathrm{~s} / \mathrm{mm}^{2}\right)$. Data postprocessing included correction for image-specific background noise [24]. Calculation of ADC was performed using the monoexponential intravoxel incoherent motion (IVIM) model [25]. Quantitative ADC images were compiled using IDL (Research Systems Inc., Boulder, CO) on a Silicon Graphics workstation (Silicon Graphics Inc., Boulder, $\mathrm{CO}$ ). Regions of interest (ROI) were selected in the parietal cortex and in the area of the basal ganglia and averaged for the calculation of the mean ADC on a MacIntosh PC equipped with the image processing software IMAGE (National Institutes of Health, Bethesda, MD). The ROIs corresponded to voxels of interest (VOI) in the same region selected for ${ }^{1} \mathrm{H}-\mathrm{MRS}$.

MR-spectra were obtained from two $6 \times 6 \times 6 \mathrm{~mm}^{3}$ VOI's using the PRESS spin-echo localization method [15]. The acquisition time per spectrum was $2.5 \mathrm{~min}$ ( $T_{\mathrm{E}}=20 \mathrm{~ms}, T_{\mathrm{R}}=2500 \mathrm{~ms}, 64$ averages). The PRESS localization was preceded by 3 CHESS water suppression cycles each using Gaussian shaped RF pulses of $25.6 \mathrm{~ms}$ duration. During the CHESS cycles crusher gradient pulses of $45 \mathrm{mT} / \mathrm{m}$ in $x$ and $90 \mathrm{mT} / \mathrm{m}$ in $y$ followed by an additional pulse of $90 \mathrm{mT} / \mathrm{m}$ in $x$ were applied. The spectra were processed on a Silicon Graphics workstation using Paravision (Bruker, Ettlingen, Germany). A $2 \mathrm{~Hz}$ Gaussian line broadening was followed by Fourier transformation and zero- and firstorder phase correction. Selected spectral lines were quantified by integration of the areas under the line over a frequency range of $\pm 0.1 \mathrm{ppm}$. Lactate measurements were taken at $1.3 \mathrm{ppm}$ and related to the peak for creatine-phosphocreatine $(\mathrm{Cr}+\mathrm{PCr})$ at $3.03 \mathrm{ppm}$ in the same spectrum in order to correct the data for fluctuations of signal reception. Since the lactate signal at 1.3 ppm is colocalized with a lipid signal, the (lactate + lipid $) /(\mathrm{Cr}+\mathrm{PCr})$-ratio was calculated.

\subsection{Bioluminescence and fluorescence imaging}

Six hours after ROSC the animals were removed from the magnet and the heads were frozen with liquid nitrogen using the funnel freezing method [26]. After removal from the skull the frozen brains were cut in the cold room at $-20{ }^{\circ} \mathrm{C}$ into four coronal slices, and subsequently cut into $20 \mu \mathrm{m}$ thin cryostat sections in the same planes as the MR images. Adjacent sections were processed for bioluminescence imaging of ATP, glucose, and lactate [27-29], and for fluorescence imaging of tissue $\mathrm{pH}$ [30]. The metabolite and the $\mathrm{pH}$ images were digitized with a charge-coupled device (CCD) camera 


\section{Perfusion-weighted imaging}

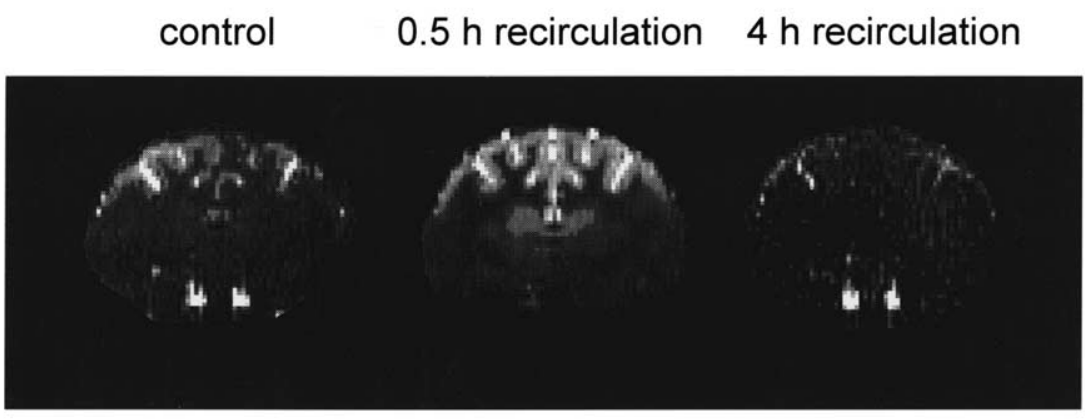

\section{ADC imaging}

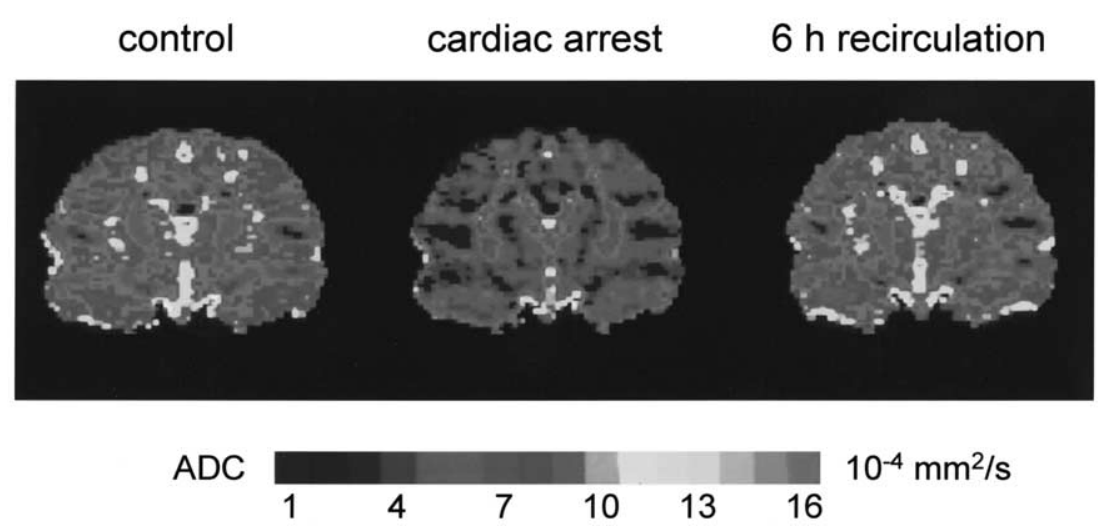

Fig. 1. Coronal arterial spin-tagging perfusion-weighted images and quantitative coronal ADC maps from a cat brain before and after 20 min of cardiocirculatory arrest. During CPR the animal received an infusion of $2 \mathrm{ml} / \mathrm{kg} 7.2 \% \mathrm{NaCl} / 6 \% \mathrm{HES}$ (HHS). Note the strong increase of the PWIsignal intensity both in the cortex and in the area of the basal ganglia during the early reperfusion period $(0.5 \mathrm{~h}$ recirculation) reflecting initial postischaemic hyperperfusion, and the very low signal intensity at $4 \mathrm{~h}$ after ROSC reflecting delayed hypoperfusion. The DWI images demonstrate reduced ADC during CA and complete normalization after $6 \mathrm{~h}$ recirculation.

connected to a MacIntosh PC, and processed with the image analysis system IMAGE. Bioluminescence images were quantified by correlating optical densities with the metabolite concentrations measured by standard enzymatic techniques in small tissue samples taken from different parts of the cryostat block. Quantification of $\mathrm{pH}$ images was performed using calibrated $\mathrm{pH}$ standards.

\subsection{Statistical analysis}

All data are expressed as means \pm standard deviation (S.D.). Changes of PWI and ADC measurements are expressed in percent of the mean baseline values. Results from ${ }^{1} \mathrm{H}$-MRS measurements of lactate, bioluminescence and fluorescence measurements, and physiological variables are given in absolute numbers. Differences in the time course of the various MR variables in the two anatomical regions were analyzed for statistical signifi- cance using a three-factorial analysis of variance (ANOVA) with a repeated measures factor and two between group factors for treatment and duration of CA (STATISTICA for Windows; StatSoft, Tulsa, OK). For post-hoc analysis the LSD-test was employed. Results from bioluminescence and fluorescence measurements, and physiological variables were compared using two-tailed Student's $t$-test. Statistical significance was assumed for $p<0.05$.

\section{Results}

\subsection{Survival rate and physiological variables}

All animals were successfully resuscitated. The mean duration of CPR was $10.1 \pm 1.1 \mathrm{~min}$ (range 8.8-11.3 min) for all animals, and ROSC was achieved in the different treatment groups after almost identical periods 
Table 1

Physiological variables after standard CPR or resuscitation in combination with HHS or TPA

\begin{tabular}{|c|c|c|c|c|c|c|c|c|c|}
\hline & \multirow[t]{2}{*}{ Prearrest } & \multicolumn{8}{|c|}{ Recirculation (min after ROSC) } \\
\hline & & 20 & 40 & 60 & 120 & 180 & 240 & 300 & 360 \\
\hline \multicolumn{10}{|c|}{$M A B P(m m H g)$} \\
\hline Standard & $101 \pm 6$ & $161 \pm 25^{*}$ & $147 \pm 16^{*}$ & $107 \pm 3$ & $98 \pm 5$ & $80 \pm 7$ & $79 \pm 6$ & $75 \pm 5$ & $75 \pm 3$ \\
\hline HHS & $96 \pm 5$ & $156 \pm 21^{\dagger}$ & $140 \pm 10^{\dagger}$ & $112 \pm 6$ & $100 \pm 4$ & $91 \pm 5$ & $87 \pm 6$ & $90 \pm 5$ & $90 \pm 7$ \\
\hline TPA & $87 \pm 5$ & $139 \pm 32^{\S}$ & $125 \pm 9^{\S}$ & $101 \pm 3$ & $94 \pm 3$ & $90 \pm 4$ & $85 \pm 6$ & $83 \pm 5$ & $82 \pm 5$ \\
\hline \multicolumn{10}{|l|}{$p H$} \\
\hline Standard & $7.35 \pm 0.02$ & $7.11 \pm 0.09^{*}$ & $7.14 \pm 0.03 *$ & $7.30 \pm 0.06^{*}$ & $7.32 \pm 0.09$ & $7.37 \pm 0.04$ & $7.33 \pm 0.05$ & $7.31 \pm 0.04$ & $7.34 \pm 0.03$ \\
\hline HHS & $7.38 \pm 0.03$ & $7.10 \pm 0.14^{\dagger}$ & $7.14 \pm 0.01^{\dagger}$ & $7.29 \pm 0.03$ & $7.37 \pm 0.03$ & $7.32 \pm 0.09$ & $7.31 \pm 0.07$ & $7.32 \pm 0.08$ & $7.33 \pm 0.04$ \\
\hline TPA & $7.35 \pm 0.02$ & $7.11 \pm 0.131^{\S}$ & $7.16 \pm 0.041^{\S}$ & $7.23 \pm 0.15$ & $7.27 \pm 0.06$ & $7.36 \pm 0.3$ & $7.37 \pm 0.06$ & $7.30 \pm 0.06$ & $7.31 \pm 0.04$ \\
\hline \multicolumn{10}{|c|}{$\mathrm{paO}_{2}(\mathrm{mmHg})$} \\
\hline Standard & $128 \pm 11$ & $333 \pm 159^{*}$ & $349 \pm 145^{*}$ & $254 \pm 70^{*}$ & $255 \pm 141^{*}$ & $216 \pm 91^{*}$ & $184 \pm 38$ & $172 \pm 32$ & $154 \pm 40$ \\
\hline HHS & $152 \pm 20$ & $358 \pm 157^{\dagger}$ & $397 \pm 175^{\dagger}$ & $428 \pm 96^{\dagger}$ & $344 \pm 82^{\dagger}$ & $208 \pm 57$ & $175 \pm 34$ & $184 \pm 50$ & $165 \pm 47$ \\
\hline TPA & $150 \pm 10$ & $321 \pm 1891^{\S}$ & $348 \pm 1481^{\S}$ & $396 \pm 1791^{\S}$ & $298 \pm 451^{\S}$ & $248 \pm 261^{\S}$ & $249 \pm 271^{\S}$ & $248 \pm 461^{\S}$ & $200 \pm 29$ \\
\hline \multicolumn{10}{|c|}{ Glucose $(m g / d l)$} \\
\hline Standard & $128 \pm 16^{8}$ & $321 \pm 33^{*, \&}$ & $416 \pm 40^{*, \&}$ & $297 \pm 43^{*, \&}$ & $231 \pm 46^{*, \&}$ & $179 \pm 27^{*, \&}$ & $222 \pm 83^{*, \&}$ & $172 \pm 58$ & $138 \pm 25$ \\
\hline HHS & $150 \pm 30^{+}$ & $299 \pm 65^{\dagger,+}$ & $372 \pm 84^{\dagger,+}$ & $319 \pm 89^{\dagger,+}$ & $238 \pm 49^{\dagger,+}$ & $224 \pm 70^{\dagger,+}$ & $206 \pm 61^{\dagger,+}$ & $183 \pm 56$ & $147 \pm 47$ \\
\hline TPA & $97 \pm 14$ & $145 \pm 711^{\S}$ & $152 \pm 441^{\S}$ & $154 \pm 46$ & $103 \pm 10$ & $89 \pm 11$ & $97 \pm 31$ & $129 \pm 49$ & $149 \pm 731^{\S}$ \\
\hline
\end{tabular}

Data are means \pm S.D. ( $n=4$ in each group).

$* p<0.05$ standard vs. baseline.

${ }^{\dagger} p<0.05$ HHS vs. baseline.

$\S p<0.05$ TPA vs. baseline;

${ }^{\&} p<0.05$ standard vs. TPA.

$+p<0.05$ HHS vs. TPA.

of ALS (standard: $9.9 \pm 1.3 \mathrm{~min}$; HHS: $10.3 \pm 1.0 \mathrm{~min}$; TPA: $9.9 \pm 1.4 \mathrm{~min})$.

Table 1 summarizes physiological variables after resuscitation using the different therapeutical regimens. In the first $40 \mathrm{~min}$ of recirculation high blood pressure due to administration of adrenaline during CPR, a

\section{Post-ischaemic hyperaemia}

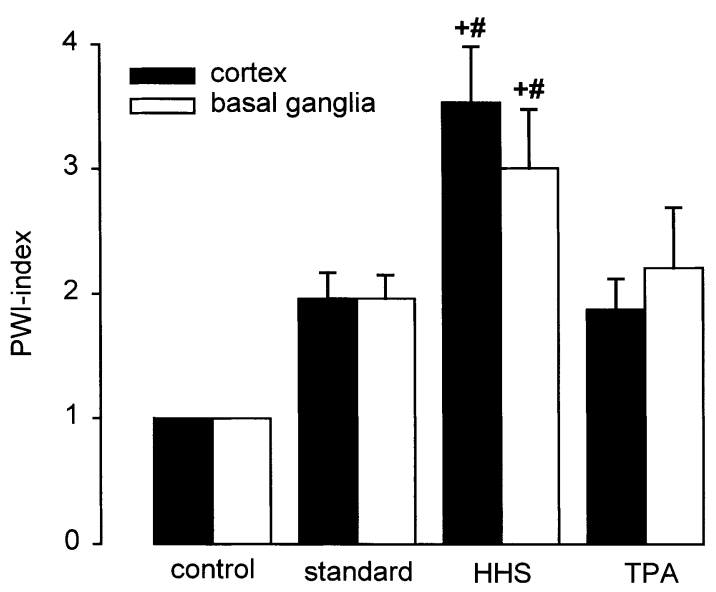

Fig. 2. PWI signal intensity in $\%$ of pre-ischaemic baseline $20 \mathrm{~min}$ after ROSC. The initial post-ischaemic cerebral recirculation was significantly higher after CPR in combination with application of an hypertonic/hyperoncotic solution than after standard resuscitation or CPR in combination with systemic fibrinolysis (TPA). Data are means \pm SEM and expressed in $\%$ of baseline.,$+ p<0.05$ HHS vs. TPA; \#, $p<0.05$ HHS vs. standard. decrease of the blood $\mathrm{pH}$, an increase of partial blood arterial oxygen pressure $\left(\mathrm{PaO}_{2}\right)$ due to ventilation with a $\mathrm{FiO}_{2}$ of 1.0, and post-ischaemic hyperglycaemia was apparent in all animals. The time courses of postischaemic MABP, blood $\mathrm{pH}$, and $\mathrm{PaO}_{2}$ were not affected by the different protocols. Blood glucose was significantly lower in TPA-treated animals already before induction of CA, and the post-ischaemic glucose level remained lower in these animals during the first $4 \mathrm{~h}$ of reperfusion. However, during the last $2 \mathrm{~h}$ of the observation period blood glucose returned to the control range and at that point in time no longer differed from the other groups.

\subsection{Perfusion-weighted imaging}

Perfusion-weighted images from a cat brain before and after $20 \mathrm{~min}$ CA demonstrate the characteristic post-ischaemic flow pattern with initial hyperperfusion after $30 \mathrm{~min}$ recirculation followed by delayed hypoperfusion after $4 \mathrm{~h}$ recirculation (Fig. 1). Treatment effects (HHS; TPA) were mainly detected in the early reperfusion period. CPR in combination with HHS induced a 3 to 3.5 -fold increase of the PWI signal intensity both in the cortex and in basal ganglia $20 \mathrm{~min}$ after ROSC but only a twofold increase in the other two groups $(p<0.05$; Fig. 2$)$. Initial hyperperfusion was prolonged after HHS treatment, in these animals a twofold increase was still present at $40 \mathrm{~min}$ after ROSC 


\section{Blood perfusion}

\section{Cortex}
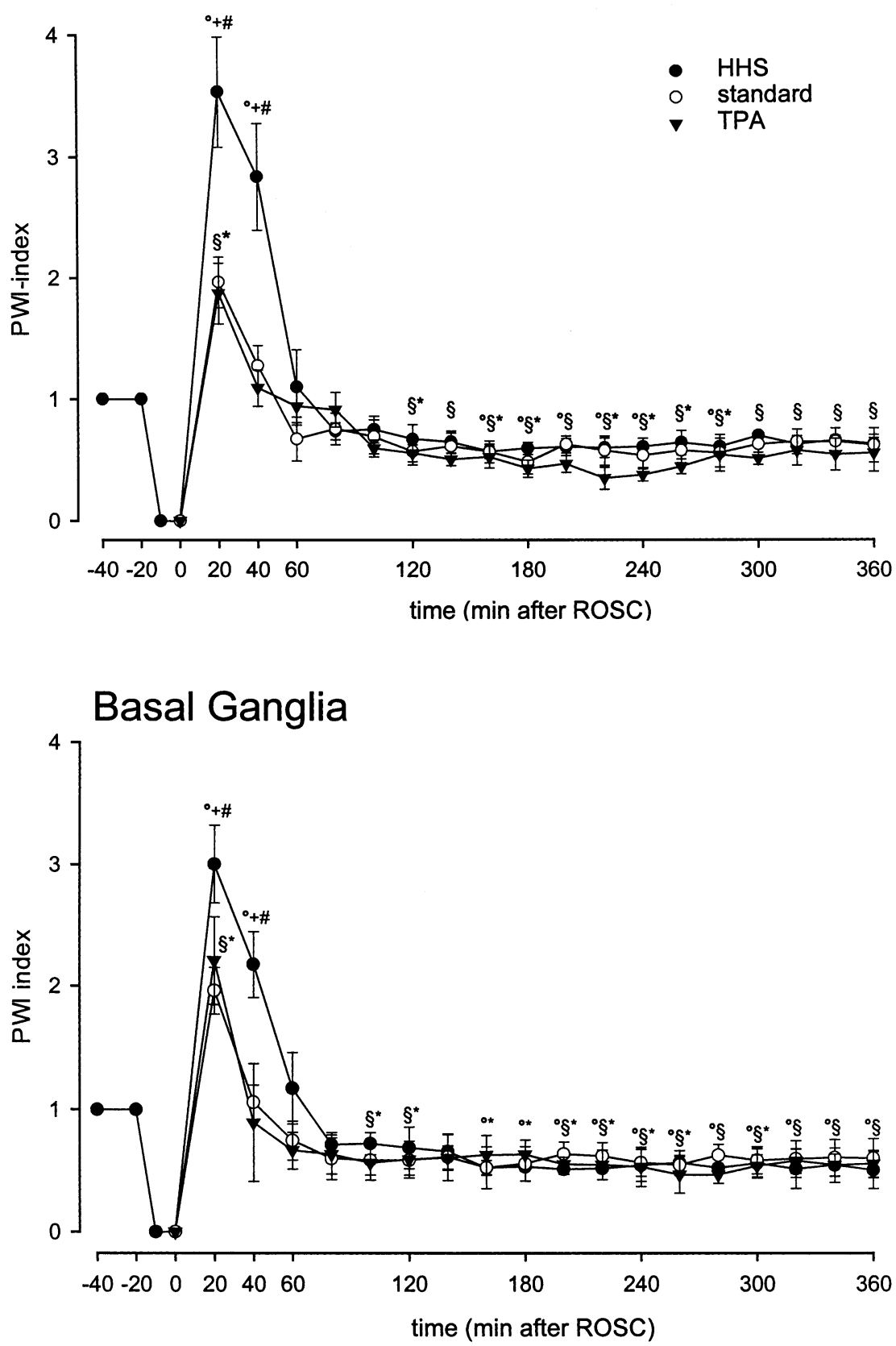

Fig. 3. Time courses of the regional PWI signal intensity in the cortex (a) and in the basal ganglia (b) before and after resuscitation from 15 to 20 min CA. Standard $=$ CPR according to AHA guidelines [20]; HHS $=$ CPR in combination with hypertonic/hyperoncotic treatment; TPA $=$ CPR in combination with systemic fibrinolysis; $n=4$ in each group. Data are means \pm S.E.M. and expressed in \% of baseline. During CA, no PWI measurements were performed. * $p<0.05$ standard vs. pre-ischaemic baseline; ${ }^{\circ}, p<0.05$ HHS vs. baseline; $\S, p<0.05$ TPA vs baseline;,$+ p<0.05$ HHS vs. TPA; $\#, p<0.05$ HHS vs. standard.

whereas $\mathrm{CBF}$ had already returned to baseline in the TPA and in the standard group ( $p<0.05$; Fig. 3 ). The drop of the signal intensities below the pre-ischaemic level approximately $80 \mathrm{~min}$ after ROSC indicated the onset of the delayed hypoperfusion. At $100-120 \mathrm{~min}$ after ROSC, the signals decreased in all groups in both anatomical regions in parallel to $45-50 \%$ of their baseline intensities $(p<0.05)$. Osmotic or fibrinolytic 


\section{Localized ${ }^{1} \mathrm{H}-\mathrm{MRS}$}
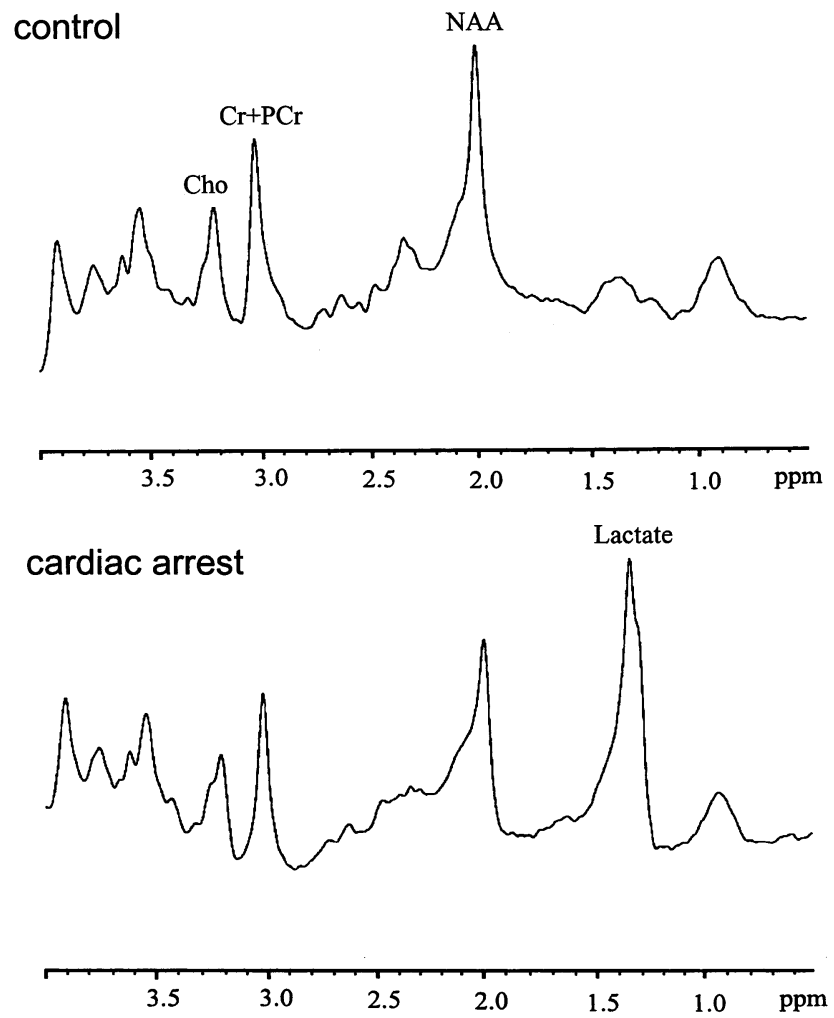

\section{$6 \mathrm{~h}$ recirculation}

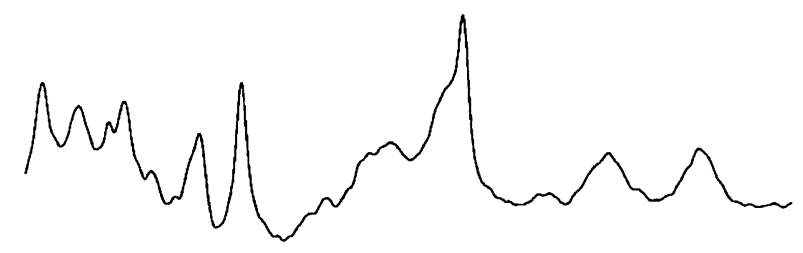

\begin{tabular}{lllllll}
\hline .5 & 3.0 & 2.5 & 2.0 & 1.5 & 1.0 & $\mathrm{ppm}$
\end{tabular}

Fig. 4. In vivo ${ }^{1} \mathrm{H}-\mathrm{MR}$ spectra of a localized volume in the cortex before and during $20 \mathrm{~min} \mathrm{CA}$, and after $6 \mathrm{~h}$ recirculation. Spectra were acquired from an animal receiving a bolus injection of $1 \mathrm{mg} / \mathrm{kg}$ TPA during CPR. Note the increase of lactate during global ischemia. With longer recirculation times lactate gradually returned to near baseline.

did not reverse hypoperfusion, but the time course differed in cortex and basal ganglia, depending on the kind of therapeutic intervention. In TPA treated cats a significant reduction of the PWI signal intensity in comparison to the prearrest level persisted in both anatomical regions until the end of the observation period $(p<0.05)$. In the cortex of standard and HHS treated animals a significant difference of the PWI intensity compared with the pre-ischaemic signal was not longer present during the last hour of evaluation, and this trend was also apparent in the basal ganglia of the standard group but not of the HHS group.

\subsection{Diffusion-weighted imaging}

Fig. 1 shows quantitative coronal ADC maps before, during, and $6 \mathrm{~h}$ after $20 \mathrm{~min}$ CA. In the cerebral cortex, ADC returned close to control, irrespective of treatment (Table 2). In the basal ganglia, in contrast, ADC recovered only in cats that received HHS or TPA, but not in animals resuscitated with the standard protocol. However, this difference between the treatment groups was not statistically significant.

\section{4. ${ }^{1} H$-spectroscopy}

In Fig. 4 in vivo ${ }^{1} \mathrm{H}-\mathrm{MR}$ spectra of a localized volume in the cortex before and during $20 \mathrm{~min} \mathrm{CA}$, and $6 \mathrm{~h}$ after successful cardiac resuscitation are demonstrated. During CA the (lactate + lipid $) /(\mathrm{Cr}+\mathrm{PCr})$-ratio increased in the cortex and the basal ganglia to an almost similar level in all groups, although the spectra were acquired later in the basal ganglia (10 min after induction of CA) than in the cortex (5 min after induction of CA) (Table $3)$. This finding demonstrates that most of the lactate derived from anaerobic glycolysis is generated within 5 min after the induction of CA, and that the calculated lactate ratio levels off at $1.59-1.75$ in the cortex and at $1.67-1.77$ in the basal ganglia (Table 3 ).

After reperfusion, the time course of this ratio differed between the two brain regions and between the different treatment groups. In the basal ganglia of HHS and standard treated animals the lactate-ratio reached its maximum during $\mathrm{CA}$ and slowly declined during recirculation to a level approximately $40 \%$ above baseline (n.s.). In the basal ganglia of the TPA group the lactate ratio further increased after initial recirculation and only gradually returned to a level which was approximately twice the resting value ( $<<.05$ vs. baseline and vs. HHS and standard). In the cortex the lactate ratio rose in all animals during the period of initial hyperperfusion, irrespective of treatment, and fell sharply after reaching its maximum $20 \mathrm{~min}$ after ROSC (Table 3). Once this initial sharp decline occured, the lactate-ratio continued to decrease in all groups but to a lower level in HHS and standard treated animals than in TPA treated cats. In the latter group the lactate ratio remained on a higher level both in the cortex and in the basal ganglia in comparison to the pre-ischaemic level $(p<0.05)$ and to the HHS treated group $(p<0.05)$ until the end of the observation period. 
Table 2

Apparent diffusion coefficient (ADC) after standard CPR or resuscitation in combination with HHS or TPA

\begin{tabular}{|c|c|c|c|c|c|c|c|c|}
\hline & \multirow[t]{2}{*}{ Prearrest } & \multicolumn{7}{|c|}{ Recirculation (min after ROSC) } \\
\hline & & 40 & 60 & 120 & 180 & 240 & 300 & 360 \\
\hline \multicolumn{9}{|l|}{ Cortex } \\
\hline Standard & 100 & $98 \pm 5$ & $98 \pm 3$ & $96 \pm 6$ & $97 \pm 4$ & $97 \pm 6$ & $95 \pm 6$ & $97 \pm 5$ \\
\hline HHS & 100 & $102 \pm 10$ & $100 \pm 8$ & $100 \pm 7$ & $99 \pm 7$ & $96 \pm 7$ & $99 \pm 8$ & $101 \pm 6$ \\
\hline TPA & 100 & $97 \pm 12$ & $97 \pm 13$ & $94 \pm 12$ & $95 \pm 12$ & $98 \pm 10$ & $99 \pm 11$ & $97 \pm 10$ \\
\hline \multicolumn{9}{|c|}{ Basal ganglia } \\
\hline Standard & 100 & $94 \pm 9$ & $93 \pm 11$ & $93 \pm 14$ & $91 \pm 11^{*}$ & $91 \pm 9^{*}$ & $92 \pm 10^{*}$ & $92 \pm 10^{*}$ \\
\hline HHS & 100 & $99 \pm 9$ & $99 \pm 7$ & $95 \pm 11$ & $94 \pm 13$ & $95 \pm 9$ & $96 \pm 8$ & $97 \pm 12$ \\
\hline TPA & 100 & $99 \pm 12$ & $97 \pm 14$ & $96 \pm 9$ & $96 \pm 8$ & $96 \pm 12$ & $96 \pm 10$ & $97 \pm 9$ \\
\hline
\end{tabular}

Data are means \pm S.D. ( $n=4$ in each group) and presented in $\%$ of mean pre-ischaemic value.

$* p<0.05$ standard vs. baseline.

\subsection{Bioluminescence imaging of tissue metabolites and fluorescence imaging of $\mathrm{pH}$}

The bioluminescence lactate measurements revealed regional tissue contents that were in agreement with the results from the ${ }^{1} \mathrm{H}-\mathrm{MRS}$ measurements of the (lactate + lipid $) /(\mathrm{Cr}+\mathrm{PCr})$-ratio. The lactate content after $6 \mathrm{~h}$ recirculation was slightly higher in basal ganglia than in the cortex in all groups (n.s.), and in TPA treated animals in comparison to the HHS group $(p<0.05$; Table 4$)$. Tissue acidity and ATP depletion were almost identical in animals resuscitated with the different resuscitation protocols. Only the glucose content in basal ganglia of HHS treated animals was higher compared with the other groups ( $p<0.05$ vs. TPA and standard; Table 4).

\section{Discussion}

This is the first study demonstrating the precise time course of cerebral reperfusion after global cerebral ischaemia in cats with the use of arterial spin tagging PWI. The spin tagging method has been shown to be sensitive to fast perfusion changes in rat brain occuring after functional activation of cerebral cortex [8] or during hypercapnia [9]. In the present study, the feasibility of serial measurements of regional cerebral perfusion with arterial spin labeling was demonstrated in a feline model of prolonged CA and CPR. During post-CA resuscitation, variations of regional $\mathrm{CBF}$ that are consistent with the previously documented change from hyper- to hypoperfusion [6] were reliably monitored both in the cortex and in the basal ganglia. The combination of arterial spin tagging PWI with DWI and localized ${ }^{1} \mathrm{H}$-MRS permitted simultaneous monitoring of regional cerebral perfusion and metabolic recovery. With this setup, a new technical approach to perform longitudinal studies of the relationship between cerebral recirculation dynamics and metabolic recovery after global and focal cerebral ischaemia has become available. Furthermore, the combination of MR imaging and spectroscopic techniques facilitates the evaluation of therapeutical approaches on brain reperfusion and metabolic recovery after cerebral ischaemia in experimental and clinical conditions. Combinations of MR techniques have been repeatedly employed to describe the temporal relationship between $\mathrm{ADC}$ and $\mathrm{CBF}$ measurements in stroke patients [31-39]. In these investigations evidence was provided that ischaemic brain lesions with severe CBF reductions were associated with lower ADC values [31-39]. Thijs et al. reported an association of low $\mathrm{ADC} / \mathrm{CBF}$ measurements with higher NIH stroke scale scores [32]; Marks et al. [34] and Kidwell et al. [35] documented amelioration of early brain reperfusion and recanalization of obstructed cerebral vessels after acute stroke and i.v. or intraarterial thrombolysis with a recombinant tissue plasminogen activator (rt-PA). In contrast to the great number of clinical studies employing MRI techniques for the evaluation of cerebral reperfusion and recovery after stroke, DWI has only rarely $[38,39]$ and PWI has never been used to monitor brain resuscitation in post-CA patients. In comatose survivors of cardiac resuscitation DWI revealed severe anoxic-ischaemic brain injury, and extensive abnormalities indicated little to no prospects for functional cerebral recovery [38]. Diffuse abnormalities were also observed in basal ganglia, cerebellum, cortex, and white matter of patients resuscitated from prolonged CA ( $>8 \mathrm{~min}$ ) [39]. DWI therefore seems to be helpful for evaluating cerebral post-ischaemic injury, and to determine the prognosis and management of these patients.

Based on these findings we tried to establish whether application of either a hypertonic/hyperoncotic solution or a plasminogen-activator during CPR was superior for 
Table 3

(Lactate \pm lipid $) /($ creatin + phosphocreatine)-ratio after standard CPR or resuscitation in combination with HHS or TPA

\begin{tabular}{|c|c|c|c|c|c|c|c|c|c|c|}
\hline & \multirow[t]{2}{*}{ Prearrest } & \multirow[t]{2}{*}{ During CA } & \multicolumn{8}{|c|}{ Recirculation (min after ROSC) } \\
\hline & & & 20 & 40 & 60 & 120 & 180 & 240 & 300 & 360 \\
\hline \multicolumn{11}{|l|}{ Cortex } \\
\hline Standard & $0.43 \pm 0.09$ & $1.75 \pm 0.36^{*}$ & $2.36 \pm 0.36^{*}$ & $1.34 \pm 0.33^{*}$ & $0.88 \pm 0.19^{*}$ & $0.95 \pm 0.17 *$ & $0.87 \pm 0.16^{*}$ & $0.73 \pm 0.10^{*}$ & $0.75 \pm 0.14^{*}$ & $0.73 \pm 0.18^{*}$ \\
\hline HHS & $0.48 \pm 0.14$ & $1.70 \pm 0.39^{\dagger}$ & $2.37 \pm 0.47^{\dagger}$ & $1.32 \pm 0.21^{\dagger}$ & $0.84 \pm 0.19^{\dagger}$ & $0.72 \pm 0.35$ & $0.86 \pm 0.17^{\dagger}$ & $0.71 \pm 0.14$ & $0.67 \pm 0.13$ & $0.61 \pm 0.12$ \\
\hline TPA & $0.44 \pm 0.07$ & $1.59 \pm 0.34^{\S}$ & $2.27 \pm 0.54^{\S}$ & $1.84 \pm 0.33^{\S, \&,+}$ & $1.17 \pm 0.29^{\S, \&,+}$ & $1.04 \pm 0.47^{\S,+}$ & $1.21 \pm 0.46^{\S, \&,+}$ & $0.87 \pm 0.18^{\S}$ & $0.86 \pm 0.10^{\S}$ & $0.86 \pm 0.12^{\S,+}$ \\
\hline \multicolumn{11}{|c|}{ Basal ganglia } \\
\hline Standard & $0.57 \pm 0.05$ & $1.71 \pm 0.26^{*}$ & $1.72 \pm 0.43 *$ & $1.41 \pm 0.33^{*}$ & $1.29 \pm 0.39 *$ & $0.92 \pm 0.07$ & $0.98 \pm 0.19^{*}$ & $1.05 \pm 0.28^{*}$ & $0.87 \pm 0.14$ & $0.82 \pm 0.28$ \\
\hline HHS & $0.54 \pm 0.08$ & $1.76 \pm 0.25^{\dagger}$ & $1.63 \pm 0.32^{\dagger}$ & $1.34 \pm 0.31^{\dagger}$ & $1.26 \pm 0.35^{\dagger}$ & $0.92 \pm 0.27$ & $0.84 \pm 0.26$ & $0.81 \pm 0.30$ & $0.82 \pm 0.24$ & $0.83 \pm 0.18$ \\
\hline TPA & $0.59 \pm 0.05$ & $1.67 \pm 0.30^{\S}$ & $1.78 \pm 0.21^{\S}$ & $1.63 \pm 0.43^{\S,+}$ & $1.34 \pm 0.19^{\S}$ & $1.19 \pm 0.17^{\S}$ & $1.22 \pm 0.36^{\S,+}$ & $1.22 \pm 0.24^{\S}+$ & $1.19 \pm 0.22^{\S, \&,+}$ & $1.13 \pm 0.08^{\S, \&,+}$ \\
\hline $\begin{array}{l}\text { Data a } \\
{ }^{*} p<0 \\
+p<0 \\
\S p<0 \\
{ }^{\dagger} p<0 \\
+\quad p<\end{array}$ & $\begin{array}{l}\text { re means } \pm \mathrm{S} \\
.05 \text { standar } \\
.05 \text { HHS vs } \\
.05 \text { TPA vs. } \\
0.05 \text { standar } \\
0.05 \text { HHS v }\end{array}$ & $\begin{array}{l}\text { S. D. }(n=4 \text { in } \\
\text { d vs. baseline } \\
\text { baseline. } \\
\text { baseline. } \\
\text { d vs. TPA. } \\
\text { s. TPA. }\end{array}$ & each group) & & & & & & & \\
\hline
\end{tabular}

circulatory and metabolic brain recovery in comparison to standard life support [20]. We could demonstrate that initial cerebral recirculation was improved after hypertonic/hyperoncotic treatment but not after systemic thrombolysis. These observations are consistent only in part with previously published studies in which both therapeutic regimes reduced significantly cerebral noreflow after CA [21,22]. Nozari et al. demonstrated a beneficial effect of a hypertonic saline-dextrane solution on CBF during CPR in combination with continuous intra-aortic balloon occlusion (IABO) in piglets [40]. However, when the hypertonic solution was applied without performing IABO, CBF did not improve [40]. Moreover, the treatment with the hypertonic solution did not ameliorate post-resuscitation cerebral hypoperfusion as confirmed by the present investigation. Systemic fibrinolysis also failed to prevent post-ischaemic hypoperfusion and made even worse metabolic recovery as indicated by an extended preservation of the anaerobic metabolism in the ${ }^{1} \mathrm{H}$-MRS measurements of the lactate-ratio and the bioluminescence images. However, the lack of amelioration of cerebral hypoperfusion with either osmotic or fibrinolytic therapy was not surprising since the pathophysiology of cerebral no-reflow and delayed hypoperfusion differs fundamentally [41]. The pathophysiology of no-reflow is multifactorial and includes vascular factors like obstruction of the capillary lumen by endothelial flaps [42] or compression by swollen perivascular glial cells [43], blood factors like viscosity changes [44], sludging of erythrocytes [45], the formation of platelet aggregates [46] or an imbalance of blood coagulation [47], and general cardiovascular factors like post-ischaemic hypotension [48]. In contrast, the protracted hypoperfusion after global cerebral ischaemia is a functional disturbance due to an increased vasotonus [41]. Reduction of the vascular tone with various vasodilating drugs $[3,48]$ yielded minor improvement of hypoperfusion, the most promising results were achieved with selective antagonists of the endothelin type A receptor $[18,49,50]$. The latter approach even improved neurological outcome after CA in Mongolian gerbils [50] and rats [19], suggesting that delayed hypoperfusion is not only an epiphenomenon of postischaemic metabolic disturbances but could be a separate pathogenic factor of cerebral recovery. However, a difference between the severity of post-ischaemic hypoperfusion between animals resuscitated in combination with thrombolytic therapy in comparison to the other two groups, standard CPR according to AHA guidelines [20] or in combination with the hypertonic/hyperoncotic solution, was not detectable and, therefore, does not explain the preservation of higher cerebral lactate in the first group. The observation of higher cerebral lactate stands also in contrast to the complete recovery of the

Table 4

Quantitative bioluminescent and fluorescent measurements

\begin{tabular}{llll}
\hline & Standard & HHS & TPA \\
\hline Cortex & & & \\
Lactate $(\mu \mathrm{mol} / \mathrm{g})$ & $4.31 \pm 2.75$ & $3.97 \pm 1.31$ & $4.61 \pm 1.54^{+}$ \\
$\mathrm{pH}$ & $7.16 \pm 0.16$ & $7.19 \pm 0.18$ & $7.09 \pm 0.25$ \\
ATP $(\mu \mathrm{mol} / \mathrm{g})$ & $2.66 \pm 0.41$ & $2.76 \pm 0.89$ & $2.52 \pm 0.64$ \\
Glucose $(\mu \mathrm{mol} / \mathrm{g})$ & $6.37 \pm 1.08$ & $6.88 \pm 2.90$ & $6.17 \pm 1.28$ \\
Basal ganglia & & & \\
Lactate $(\mu \mathrm{mol} / \mathrm{g})$ & $4.37 \pm 1.79$ & $4.15 \pm 1.90$ & $4.91 \pm 1.72^{+}$ \\
pH & $7.15 \pm 0.14$ & $7.14 \pm 0.17$ & $7.08 \pm 0.21$ \\
ATP $(\mu \mathrm{mol} / \mathrm{g})$ & $2.44 \pm 0.73$ & $2.66 \pm 0.38$ & $2.44 \pm 0.62$ \\
Glucose $(\mu \mathrm{mol} / \mathrm{g})$ & $6.40 \pm 1.76$ & $7.74 \pm 2.59^{+, \#}$ & $6.66 \pm 2.48$ \\
\hline
\end{tabular}

Data are means \pm S.D. $(n=4$ in each group $)$; ATP, adenosine triphosphate.

$+p<0.05$ HHS vs. TPA.

\# $p<0.05$ standard vs. HHS. 
ADC in diffusion-weighted images indicating restoration of cerebral water and ion homeostasis in the TPA treated animals. Because no differences of systemic factors like duration of $\mathrm{CPR}$, adrenaline dosage during CPR, haemodynamic or systemic metabolic recovery after restoration of circulation was present between the experimental groups, we cannot provide a good explanation for the higher cerebral lactate after TPA treatment. Since the present investigation was the first study in which the effects of thrombolysis during CPR on cerebral metabolic recovery were assessed, this observation has to await confirmation. The higher cerebral lactate clearly stands in contrast to our previous experimental documentation of an improved reflow [22] and to a clinical study describing the successful use of TPA during CPR with higher hospital discharge and good neurological outcome [51].

Two important limitations of the present investigation have to be discussed. Despite statistically significant differences between the experimental groups in various variables, it has to be considered that only four animals were included in each experimental group. Therefore, the conclusions drawn from the results lack of statistical power. This has to be considered in the discussion of the observation of higher cerebral lactate after CPR in combination with TPA treatment. One animal in this group recovered poorly throughout the observation period after resuscitation from 20 min CA. Finally, it has to be mentioned that, originally, CA was induced for $25 \mathrm{~min}$ in six additional animals. Only three animals after $25 \mathrm{~min}$ CA were successfully resuscitated, both animals from the TPA group and one animal from the HHS group. Because no animal from the standard group was successfully resuscitated a comparison of the variables between the experimental groups was not possible and, therefore, the data of these animals were not presented.

In conclusion, the present investigation demonstrates that the combination of arterial spin-tagging PWI with DWI and localized ${ }^{1} \mathrm{H}$-MRS enables to perform longitudinal studies of the relationship between cerebral recirculation dynamics and metabolic recovery after global cerebral ischaemia. With this set-up, it was demonstrated that initial cerebral recirculation was improved after hypertonic-hyperosmotic treatment. Moreover, osmotic and thrombolytic therapy were ineffective in preventing or ameliorating post-ischaemic delayed hypoperfusion. Whether the two therapeutic regimens are superior for long-term brain recovery compared with the standard protocol in clinical use depends on the pathophysiological importance of postischaemic hypoperfusion. As long as this disturbance is not reversed, the improvements presented here will only be the first step towards a more efficient haemodynamic therapy of post-ischaemic brain resuscitation.

\section{Acknowledgements}

The authors wish to thank Mrs. M. Jagodnik for excellent technical help and Mrs. D. Schewetzky for excellent secretarial help. The artwork was prepared by Mr. B. Huth. The study was supported by a grant from the Deutsche Forschungsgemeinschaft (SFB 194/B1).

\section{References}

[1] Herlitz J, Ekstrom L, Wennerblom B, Axelson A, Bang A, Holmberg S. Risk indicators for, and symptoms associated with death among patients hospitalized after out-of-hospital cardiac arrest. Coron Artery Dis 1994;5:407-14.

[2] Ames RL, Wright M, Kowada JM, Thurston JM, Majno G. Cerebral ischemia. II. The no-reflow phenomenon. Am J Pathol 1968;52:437-53.

[3] Hossmann KA, Lechtape-Grüter H, Hossmann V. The role of cerebral blood flow for the recovery of the brain after prolonged ischemia. Zeitsch Neurol 1973;204(4):281-99.

[4] Fischer M, Hossmann KA. No-reflow after cardiac arrest. Intensive Care Med 1995;21:132-41.

[5] Zimmer R, Lang R, Oberdörster G. Post-ischemic reactive hyperemia of the isolated, perfused brain of the dog. Pflügl Arch 1971;328:332-43.

[6] Suzuki R, Yamaguchi T, Kirino T, Orzi F, Klatzo I. The effects of 5 -min ischemia in Mongolian gerbils. I. Blood-brain barrier, cerebral blood flow, and local cerebral glucose utilization changes. Acta Neuropathol 1983;60:207-16.

[7] Schmidt-Kastner R, Ophoff BG, Hossmann KA. Delayed recovery of $\mathrm{CO}_{2}$ reactivity after one hour's complete ischaemia of cat brain. J Neurol 1986;233(6):367-9.

[8] Kerskens CM, Hoehn-Berlage M, Schmitz B, Busch E, Bock C, Gyngell ML, et al. Ultrafast perfusion-weighted MRI of functional brain activation in rats during forepaw stimulation: comparison with T2*-weighted MRI. NMR Biomed 1996;8:20-3.

[9] Forbes ML, Hendrich KS, Kochanek PM. Assessment of cerebral blood flow and $\mathrm{CO}_{2}$-reactivity after controlled cortical impact by perfusion magnetic resonance imaging using arterial spin-labeling in rats. J Cereb Blood Flow Metab 1997;17(6):865-74.

[10] Benveniste H, Hedlund LW, Johnson GH. Mechanism of detection of acute cerebral ischemia in rats by diffusion-weighted magnetic resonance microscopy. Stroke 1992;23:746-54.

[11] Fischer M, Bockhorst K, Hoehn-Berlage M, Hossmann KA. Imaging of the apparent diffusion coefficient for the evaluation of cerebral metabolic recovery after cardiac arrest. Magn Reson Imaging 1995;13(6):781-90.

[12] Hossmann KA, Fischer M, Bockhorst K, Hoehn-Berlage M. NMR imaging of the apparent diffusion coefficient (ADC) for the evaluation of metabolic suppression and recovery after prolonged cerebral ischemia. J Cereb Blood Flow Metab 1994;14(5):723-31.

[13] Minematsu K, Li L, Sotak CH, Davis MA, Fisher M. Reversible focal ischemic injury demonstrated by diffusion-weighted magnetic resonance imaging in rats. Stroke 1992;23(9):1304-10.

[14] Behar KL, Rothman DL, Hossmann KA. NMR spectroscopic investigation of the recovery of energy and acid-base homeostasis in the cat brain after prolonged ischemia. J Cereb Blood Flow Metab 1989;9(5):655-65.

[15] Gyngell ML, Busch E, Schmitz B, Kohno K, Back T, HoehnBerlage M, Hossmann KA. Evolution of acute focal cerebral ischemia in rats observed by localized ${ }^{1} \mathrm{H}$ MRS, diffusion- 
weighted MRI, and electrophysiological monitoring. NMR Biomed 2001;8:206-14.

[16] Hossmann KA. Resuscitation potentials after prolonged global cerebral ischemia in cats. Crit Care Med 1988;16:964-71.

[17] Osburne RC, Halsey JH. Cerebral blood flow: a predictor of recovery from ischemia in the gerbil. Arch Neurol 1975;32:45761.

[18] Krep H, Brinker G, Pillekamp F, Hossmann KA. Treatment with an endothelin type A receptor-antagonist after cardiac arrest and resuscitation improves cerebral hemodynamic and functional recovery in rats. Crit Care Med 2000;28:2866-72.

[19] Krep H, Brinker G, Schwindt W, Hossmann KA. Endothelin type A antagonist improves long-term neurologic recovery after cardiac arrest in rats. Crit Care Med 2000;28:2873-80.

[20] American Heart Association. Guidelines for cardiopulmonary resuscitation and emergency cardiac care. Emergency Cardiac Care Committee and Subcommittees, American Heart Association. Part III. Adult advanced cardiac life support. J Am Med Assoc 1992;268:2199-241.

[21] Fischer M, Hossmann KA. Volume expansion during cardiopulmonary resuscitation reduces cerebral no-reflow. Resuscitation 1996;32(3):227-40.

[22] Fischer M, Böttiger BW, Popov-Cenic S, Hossmann KA. Thrombolysis using plasminogen activator and heparin reduces cerebral no-reflow after resuscitation from cardiac arrest-an experimental study in the cat. Intensive Care Med 1996;22(11):1214-23

[23] Pekar J, Jezzard P, Roberts DA, Leigh JS, Jr, Frank JA, McLaughlin AC. Perfusion imaging with compensation for asymetric magnetization transfer effects. Magn Reson Med 1996;35(1):70-9.

[24] Eis M, Hoehn-Berlage M. Correction of gradient crosstalk and optimization of measurement parameters in diffusion MR imaging. J Magn Reson 1995;107:222-34.

[25] LeBihan D, Breton E, Lallemand D, Aubin ML, Vignaud L, Laval-Jeantat M. Separation of diffusion and perfusion in intravoxel incoherent motion MR imaging. Radiology 1988;168:497-505.

[26] Ponten U, Ratcheson RA, Salford LG, Siesjkö BK. Optimal freezing conditions for cerebral metabolites in rats. J Neurochem 1973;21:1127-38.

[27] Paschen W, Hossmann KA, van den Kerckhoff W. Regional assessment of energy-producing metabolism following prolonged complete ischemia of cat brain. J Cereb Blood Flow Metab 1983;3(3):321-9.

[28] Paschen W. Regional quantitative determination of lactate in brain sections. A bioluminescent approach. J Cereb Blood Flow Metab 1985;5(4):609-12.

[29] Paschen W, Mies G, Kloiber O, Hossmann KA. Regional quantitative determination of brain glucose in tissue sections: a bioluminescent approach. J Cereb Blood Flow Metab 1985;5(3):465-8.

[30] Csiba L, Paschen W, Hossmann KA. A topographic quantitative method for measuring brain tissue $\mathrm{pH}$ under physiological and pathophysiological conditions. Brain Res 1983;289:334-7.

[31] Lin W, Lee JM, Lee YZ, Vo KD, Pilgram T, Hsu CY. Temporal relationship between apparent diffusion coefficient and absolute measurements of cerebral blood flow in acute stroke patients. Stroke 2003;34:64-70.

[32] Thijs VN, Adami A, Neumann-Haefelin T, Moseley ME, Albers GW. Clinical and radiological correlates of reduced cerebral blood flow measured using magnetic resonance imaging. Arch Neurol 2002;59:233-8.
[33] Thijs VN, Adami A, Neumann-Haefelin T, Moseley ME, Marks MP, Albers GW. Relationship between severity of MR perfusion deficit and DW lesion evolution. Neurology 2001;57:1205-11.

[34] Marks MP, Tong DC, Beaulieu C, Albers GW, de Crespigny A, Mosele ME. Evaluation of early reperfusion and i.v. tPA therapy using diffusion- and perfusion-weighted MRI. Neurology 1999;52:1792-8.

[35] Kidwell CS, Saver JL, Mattiello J, Starkman S, Vinuela F, Duckwiler G, et al. Diffusion-perfusion MRI characterization of post-recanalization hyperperfusion in humans. Neurology 2001;57:2015-21.

[36] Fiehler J, Knab R, Reichenbach JR, Fitzek C, Weiller C, Rother J. Apparent diffusion coefficient decreases and magnetic resonance imaging perfusion parameters are associated in ischemic tissue of acute stroke patients. J Cereb Blood Flow Metab 2001;21:577-84.

[37] Ueda T, Yuh WT, Maley JE, Quets JP, Hahn PY, Magnotta VA. Outcome of acute ischemic lesions evaluated by diffusion and perfusion MR imaging. Am J Neuroradiol 1999;20:983-9.

[38] Wijdicks EF, Campeau NG, Miller GM. MR imaging in comatose survivors of cardiac resuscitation. Am J Neuroradiol 2001;22:1561-5.

[39] Arbelaez A, Castillo M, Mukherji SK. Diffusion-weighted MR imaging of global cerebral anoxia. Am $\mathbf{J}$ Neuroradiol 1999;20:999-1007.

[40] Nozari A, Rubertsson S, Gedeberg R, Nordgren A, Wiklund L. Maximisation of cerebral blood flow during experimental cardiopulmonary resuscitation does not ameliorate post-resuscitation hypoperfusion. Resuscitation 1999;40:27-35.

[41] Hossmann KA. Reperfusion of the brain after global ischemiahemodynamic disturbances. Shock 1997;8(2):95-101.

[42] Arsenio-Nunes ML, Hossmann KA, Farkas-Bargeton E. Ultrastructural and histochemical investigation of the cerebral cortex of cat during and after complete ischemia. Acta Neuropathol 1973;26:329-44.

[43] Chiang J, Kowada M, Ames A, Wright RL, Majno G. Cerebral ischemia. III. Vascular changes. Am J Pathol 1968;52:455-76.

[44] Fischer EG, Ames A, Lorenzo AV. Cerebral blood flow immediately following brief circulatory stasis. Stroke 1979;10:423-7.

[45] Hekmatpanah J. Cerebral blood flow dynamics in hypotension and cardiac arrest. Neurology 1973;23:174-80.

[46] Obrenovitch TP, Hallenbeck JM. Platelet accumulation in regions of low blood flow during the post-ischemic period. Stroke 1985;16:224-34.

[47] Böttiger BW, Motsch J, Böhrer H, Boker T, Aulmann M, Nawroth PP, et al. Activation of blood coagulation following cardiac arrest is not adequately balanced by activation of endogenous fibrinolysis. Circulation 1995;92:2572-8.

[48] Takagi S, Cocito L, Hossmann KA. Blood recirculation and pharmacological responsiveness of the cerebral vasculature following prolonged ischemia of cat brain. Stroke 1977;8:707-12.

[49] Spatz M, Yasuma Y, Strasser A, McCarron RM. Cerebral postischemic hypoperfusion is mediated by ETA receptors. Brain Res 1996;726:242-6.

[50] Lehmberg J, Putz C, Furst M, Beck J, Baethmann A, Uhl E. Impact of the endothelin-A receptor antagonist BQ610 on microcirculation in global cerebral ischemia and reperfusion. Brain Res 2003;961:277-86.

[51] Böttiger BW, Bode C, Kern S, Gries A, Gust R, Glatzer R, et al. Efficacy and safety of thrombolytic therapy after initially unsuccessful cardiopulmonary resuscitation: a prospective clinical trial. Lancet 2001;357:1550-83. 